\title{
Metabolic Coupling between Glia and Neurons
}

\author{
Marco Tsacopoulos ${ }^{1}$ and Pierre J. Magistretti ${ }^{2}$ \\ 1Laboratoire d'Ophthalmologie Expérimentale, Département de Physiologie, Faculté de Médecine, Université de Genève, \\ $\mathrm{CH}-1206$ Genève, and 'Laboratoire de Recherche Neurologique, Institut de Physiologie et Service de Neurologie du \\ CHUV, Faculté de Médecine, Université de Lausanne, CH-1005 Lausanne, Switzerland
}

The concept of a metabolic coupling between neurons and glia, particularly astrocytes, geared at maintaining energy metabolism homeostasis in the brain has been entertained for some time. The first element of this concept emerged from the analysis of the cytological relationships cxisting among capillarics, astrocytcs, and the neuropil (Fig. 1). Indeed, based on the observation that specialized astrocytic processes, the end-feet, are interposed between virtually all brain capillaries and neuronal processes, it was postulated over a century ago that astrocytes represented the primary route for the transfer of metabolic substrates from the circulation to the neuropil (Golgi, 1886; Sala, 1891). A lucid formulation of this concept was presented by Andriezen (1893): "The development of a felted sheath of neuroglia fibers in the ground-substance immediately surrounding the blood vessels of the Brain seems therefore ... to allow of the free passage of lymph and metabolic products which enter into the fluid and general metabolism of the nerve cells." Although this appealing concept has been discussed critically throughout the literature over decades (Nicholls et al., 1992), functional evidence for specific molecular and cellular processes supporting this concept has been lacking, and the nature of the metabolic substrates distributed by astrocytes to neurons remains elusive. Because glucose is the almost exclusive energy source of the brain, an unanswered question has been whether the function of astrocytes is restricted to glucose uptake and to its distribution, without further metabolic processing, to neurons, or whether astrocytes release a metabolic intermediate of glucose. The major obstacle for functional studies aimed at resolving this question has been the diticulty of achieving the cellular resolution necessary to monitor metabolic fluxes between the highly intermingled neuronal and glial processes in the intact brain. This obstacle has been overcome in recent years by using simple and well compartmentalized neural systems such as the retina, or purified cellular preparations of neurons and glia.

In this article, we will review the evidence obtained from studies carried out (1) in primary cultures of astrocytes or neurons prepared from mouse cerebral cortex, and (2) in the honeybee drone retina and in the juvenile guinea pig retina. The view that emerges from these studics confirms, and in fact extends, the concept put forward over a century ago. Thus, astrocytes are indeed the

This work was supported by Swiss National Science Foundation Grants 3139426.93 (M.T.) and 31-40565.94 (P.J.M.). We thank Drs. S. Poitry, C. PoitryYamate, and A.-L. Veuthey, and L. Pellerin and $U$. Sorg for their contribution to the experimental work described in this review; we also thank P. Perrottet and $M$. Maillard for technical assistance.

Correspondence should be addressed to Pierre J. Magistretti, Institut de Physiologie, Faculté de Médecine, 7 Rue du Bugnon, CH-1005 Lausanne, Switzerland.

Copyright $\mathbb{C} 1996$ Society for Neuroscience $0270-6474 / 96 / 160877-09 \$ 05.00 / 0$ primary site of glucose uptake during neuronal activity; however, glucose does not transit unmetabolized through astrocytes for distribution to the neuropil, as was postulated by Sala (1891) and by Golgi (1886). Rather, glucose is processed glycolytically in astrocytcs, which relcasc lactatc (or alaninc in the inscct retina) as the metabolic substrate to be used by neurons. These experimental data indicate a remarkable metabolic compartmentation between astrocytes and neurons, which is corroborated by the selective distribution of certain enzymatic activities in either cell type. In addition, they provide the cellular basis for unexpected findings obtained by functional-brain imaging techniques, such as positron emission tomography (PET) (Fox and Raichle, 1986; Fox et al., 1988) and ${ }^{1} \mathrm{H}$ magnetic resonance spectroscopy (MRS) (Prichard et al., 1991), which consistently indicate the occurrence of glyco lysis during neuronal activity. The converging set of results obtained under diverse experimental conditions and in different cellular preparations provides strong arguments for revising the view that glial cells simply represent a cellular mass filling the spaces between neurons and providing a preferential, but metabolically inert, route for the passage of glucose from the circulation to neurons. That glycogen, the storage form of glucose, is localized almost exclusively in astrocytes is further evidence for an active metabolic processing of glucose by this cell type (for review, see Magistretti et al., 1993). Glycogenolysis in astrocytes is under tight control of specific neurotransmitters that can mobilize it, via receptor-mediated mechanisms, during neuronal activity (Magistretti et al., 1993).

\section{Uptake and phosphorylation of glucose by glial cells during neuronal activity}

The first evidence for and quantitative assessment of the prevalent uptake and phosphorylation of glucose by glial cells during neuronal activity was provided in the honeybee drone retina. A unique feature of this preparation is its crystal-like structure and metabolic compartmentation. In this neural preparation, modular, rosette-like structures, made up of six photoreceptor neurons that respond directly to light stimulation, are surrounded by one type of glial cell, the outer pigment cell (Fig. 2). In addition to this structural segregation, the metabolic compartmentation of glia and neurons is remarkable. Photoreceptor neurons are enriched in mitochondria and virtually devoid of glycogen, whereas the reverse is the case in glial cells (Tsacopoulos et al., 1987). Energy metabolism in photoreceptors is exclusively aerobic, because anoxia or the inhibitor of mitochondrial respiration amobarbital abolish their light-induced electrical activity in a few seconds (Dimitracos and Tsacopoulos, 1985).

Uptake and phosphorylation of glucose by a tissue can be determined quantitatively by monitoring the accumulation of 
Figure 1. Schematic representation of the cytological relationships existing among intraparenchymal capillaries, astrocytes, and the neuropil. Astrocyte processes surround capillaries (end-feet) and ensheath synapses; in addition, receptors and uptake sites for neurotransmitters are present on astrocytes. These features make astrocytes ideally suited to sense synaptic activity $(A)$ and to couple it with uptake and metabolism of energy substrates originating from the circulation $(B)$.

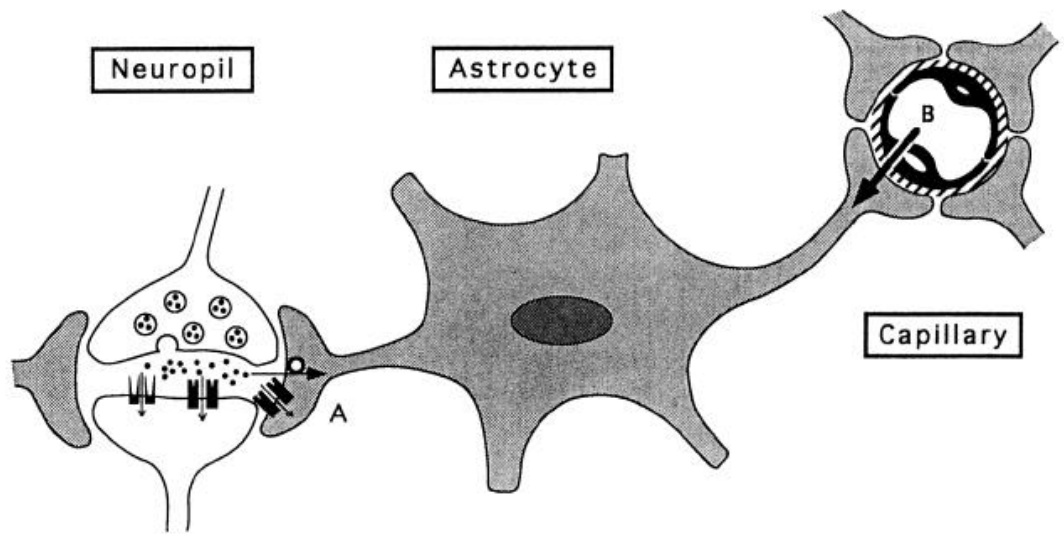

[ $\left.{ }^{3} \mathrm{H}\right] 2$-deoxyglucose (2-DG) (Sokoloff et al., 1989). 2-DG is an analog of glucose, which is transported into cells through glucose transporters and phosphorylated by hexokinase. The $\left[{ }^{3} \mathrm{H}\right] 2-\mathrm{DG}-$ phosphate (2-DG-P) that is formed is not metabolized further and accumulates intracellularly, thus providing a quantitative assessment of glucose utilization by a tissue (Sokoloff et al., 1977). Using this technique, glucose uptake and phosphorylation have been determined in honeybee drone retinal slices maintained in a physiological solution. The accumulation of 2-DG-P proceeds linearly over $60 \mathrm{~min}$ at a rate of $6 \mu \mathrm{mol} / \mathrm{hr}$ and shows a $K_{\mathrm{m}}$ (combined for uptake and phosphorylation) of $1.6 \mathrm{~mm}$, a value of the same order of magnitude as that found in the mammalian brain (Tsacopoulos et al., 1988). Most importantly, quantitative autoradiography unequivocably indicates that the accumulation of ${ }^{3} \mathrm{H}$ label (verified by HPLC to correspond to 2-DG-P) occurs exclusively in glial cells. Photoreceptors, by contrast, are labeled only at background levels (Fig. $2 a$ ). These observations indicate that the uptake and phosphorylation of glucose occur almost exclusively in the glial cells of this nervous tissue. Indeed, subcellular localization of hexokinase and measurement of hexokinase activity in purified suspensions of freshly isolated glial cells or photoreceptors indicated that nearly all hexokinase activity is confined in the cytosolic fraction of glial cells (Veuthey et al., 1994). During photostimulation, this metabolic compartmentation is maintained. Photoreceptor neurons, not glial cells, contain the visual pigment rhodopsin and, therefore, are the only cells in the retina directly excitable by light. Accordingly, repetitive photostimulation increases oxygen consumption of photoreceptors from 38 to $160 \mu \mathrm{l}$ of $\mathrm{O}_{2} \cdot \mathrm{ml}$ of photoreceptor ${ }^{-1} \cdot \min ^{-1}$; yet there is a $50 \%$ increase in 2-DG uptake and phosphorylation exclusively localized in the glial cells (Tsacopoulos and Poitry, 1982; Brazitikos and Tsacopoulos, 1991). This observation raises two important questions. First, because glial cells cannot be activated directly by light, is there a signal released from the activated photoreceptors to trigger glucose uptake and phosphorylation in the glial cells? Second, is the increased oxygen consumption of photoreceptor neurons accounted for by their oxidation of a metabolic substrate released by the glial cells? The first question has not been answered definitively for the honeybee drone retina, although $\mathrm{NH}_{4}^{+}$is a strong candidate for a signal released by the photoreceptors (Tsacopoulos and Poitry, 1995). In mammalian neural tissue, strong evidence points to glutamate as the coupling signal between neuronal activation and glucose uptake by astrocytes (Pellerin and Magistretti, 1994; Takahashi et al., 1995). Regarding the second question, alanine has been identified as the metabolic substrate released by glial cells of the honeybee drone retina during photoreceptor activation. Evidence supporting this will be detailed below.

A similar metabolic coupling between glial cells and neurons has been demonstrated in the guinea pig retina. Although not as completely compartmentalized from the structural viewpoint as the honeybee drone retina, astrocytes (Müller cells) can be identified easily in histological sections of this mammalian central nervous system structure. Using a combination of biochemical and autoradiographic techniques described previously for the honeybee drone retina, evidence has been obtained for a predominant 2-DG uptake into Müller cells under both basal and lightstimulated conditions (Poitry-Yamate and Tsacopoulos, 1991). These observations, obtained in whole retina, were confirmed in a highly purified preparation consisting exclusively of Müller cells freshly isolated from juvenile guinea pig retinas. This preparation showed intensive labeling of individual cells exposed to 2-DG that was subject to inhibition by the glycolysis inhibitor iodoacetate (Poitry-Yamate and Tsacopoulos, 1992).

Further clarification of the biochemical mechanisms underlying cell-specific metabolic fluxes between glia and neurons has been provided recently in purified preparations consisting of primary cultures of astrocytes or neurons isolated from rodent brain. In general, the basal rate of glucose utilization has been reported to be higher in astrocytes than in neurons (Lopes-Cardozo et al., 1986); in mouse cerebral cortical cultures, values are $\sim 20 \mathrm{nmol}$. $\mathrm{mg}$ of protein ${ }^{-1} \cdot \mathrm{min}^{-1}$ for astrocytes and $\sim 10 \mathrm{nmol} \cdot \mathrm{mg}$ of protein $^{-1} \cdot \min ^{-1}$ for neurons (Pellerin et al., 1995). These values are of the same order of magnitude as those determined in vivo for cortical gray matter using the 2-DG autoradiographic technique (Sokoloff et al., 1977).

The contribution of astrocytes to glucose utilization during neuronal activity is even more striking. Indeed, astrocytes are ideally positioned to provide coupling between neuronal activity and glucose uptake. As noted in the introductory remarks, astrocyte end-feet surround intraparenchymal capillaries, which are the source of glucose. This cytoarchitectural arrangement implies that astrocytes form the first cellular barrier that glucose entering the brain parenchyma encounters, and it makes astrocytes a likely site of primary glucose uptake (Fig. 1). Another feature of astrocytes is the existence of processes that ensheath synaptic contacts (Peters et al., 1991). The recent demonstration of neurotransmitter receptors and uptake sites on astrocytes suggests that astrocytes are geared to sense synaptic activity (Barres, 1991; Murphy, 1993). In fact, two well established functions of astrocytes are the clearance of potassium and the uptake of glutamate, both of which increase in the extracellular space in conjunction with synaptic 

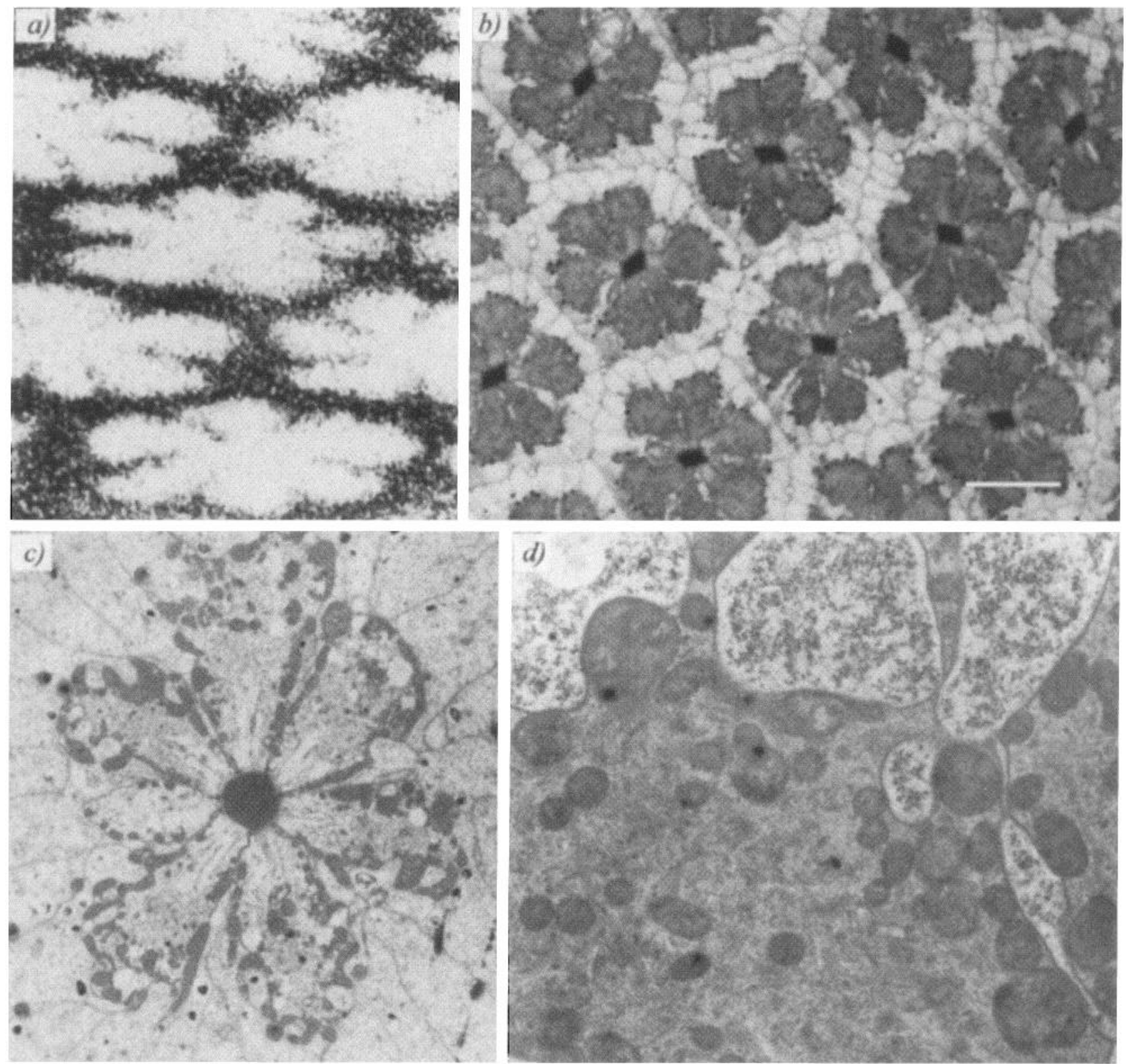

Figure 2. a, Autoradiograph of a slightly oblique section prepared from a slice of honeybee drone retina previously incubated with [ $\left.{ }^{3} \mathrm{H}\right] 2-\mathrm{DG}$ for $60 \mathrm{~min}$ and then washed for $30 \mathrm{~min}$. Only glial cells wrapping the photoreceptors (rosettes) are heavily stained with $\left[{ }^{3} \mathrm{H}\right] 2-\mathrm{DG}-\mathrm{P}$ (magnification, $720 \times$ ). $b$, Light micrograph of a section almost perpendicular to the axes of the ommatidia. The rosettes are the retinulae, clusters of six photoreceptor cells. The dark lozenge at the center of each retinula is the rhabdom, made of microvilli contributed by each of the photoreceptors. The visual pigment rhodopsin is packed in the microvilli. The pale cells between the retinulae are glial cells. Staining was done with Toluidine blue. (magnification, $640 \times$; scale bar, $20 \mu \mathrm{m}$ ). $c$, Electron micrograph showing a cross-section through part of an intact retina, nearly perpendicular to the long axes of six large photoreceptor cells forming one retinula. The photoreceptors contain many mitochondria oriented at the periphery of the cell. Glial cells surrounding photoreceptors contain almost no mitochondria (magnification, $1200 \times$ ). $d$, Slightly oblique section. The use of $\mathrm{OsO}_{4}$ in Millonig buffer (Veuthey et al., 1994) reveals the glycogen granules filling a glial process. Note the vicinity of mitochondria and glycogen granules, separated by the cytoplasmic membranes of the photoreceptors and glial cells (magnification, $11,000 \times$ ).

activation (Kuffler et al., 1966; Barres, 1991). During physiological stimulation of a given cortical area, glutamate is released from the axon terminals of activated excitatory pathways (Fonnum, 1984; Danbolt, 1994). In vitro, activation, therefore, can be mimicked by exposure of cells to relevant concentrations of glutamate, and glucose uptake and phosphorylation can be monitored via the 2-DG technique. Indeed, glutamate stimulates 2-DG uptake and phosphorylation by astrocytes, with an $\mathrm{EC}_{50}$ of $\sim 70 \mu \mathrm{M}$ (Pellerin and Magistretti, 1994). This effect is not mediated by the glutamate receptors present on astrocytes (Pearce, 1993); rather, stim- ulation involves activation of glutamate transporters (Pellerin and Magistretti, 1994; Takahashi et al., 1995). Three main types of glutamate transporters have been characterized (Kanner, 1993; Danbolt, 1994; Kanai et al., 1994): EAAC1, which is neuronspecific $\left(\mathrm{EC}_{50}=1 \mu \mathrm{M}\right)$; GLT1, which is present exclusively on astrocytes $\left(\mathrm{EC}_{50}=10 \mu \mathrm{M}\right)$; and GLAST, which is present on both neurons and astrocytes $\left(\mathrm{EC}_{50}=50-70 \mu \mathrm{M}\right)$. The uptake of glutamate by these transporters is coupled to the inward transport of $2-3 \mathrm{Na}^{+}$ions per glutamate molecule (Bouvier et al., 1992). Thus, glutamate uptake into astrocytes causes an increase in the intra- 
Figlure 3. Schematic representation of the mechanism for glutamate-induced glycolysis in astrocytes during physiological activation. At glutamatergic synapses, presynaptically released glutamate depolarizes postsynaptic neurons by acting at specific receptor subtypes. The action of glutamate is terminated by an cfficient glutamate-uplake system located primarily in astrocytes. Glutamate is cotransported with $\mathrm{Na}^{+}$, causing an increase in the intra-astrocytic concentration of $\mathrm{Na}^{i}$, leading to an activation of the astrocyte $\mathrm{Na}^{+} / \mathrm{K}^{+}$-ATPase. Activation of $\mathrm{Na} / \mathrm{K}^{+}$-ATPase stimulates glycolysis, i.c., glucose utilization and laclate production (Parker and Hoffman, 1967; Lipton and Hcimbach, 1978; Paul et al., 1979; Lynch and Balaban, 1937). Lactate, once released by astrocytes, can be taken up by neurons and serve them as an adequate energy substrate (for graphic clarity, only lactate uptake into presynaptic terminals is indicated; however, this process also could occur at the postsynaptic neuron). In accord with recent evidence, glutamate receptors also are shown on astrocytes (Pearce, 1993). This model, which summarizes in vitro experimental evidences indicating glutamate-induced glycolysis, reflects cellular and molecular events occurring during activation of a given cortical area (arrow labeled $A$ for activation). Direct glucose uptake into neurons under basal conditions also is shown (amow labeled $B$ for basal conditions): $P y r$, pyruvate; Lac, lactate; Gln, glutamine; G, G-protein. [Taken from Pellerin and Magistretti (1994) with permission.]

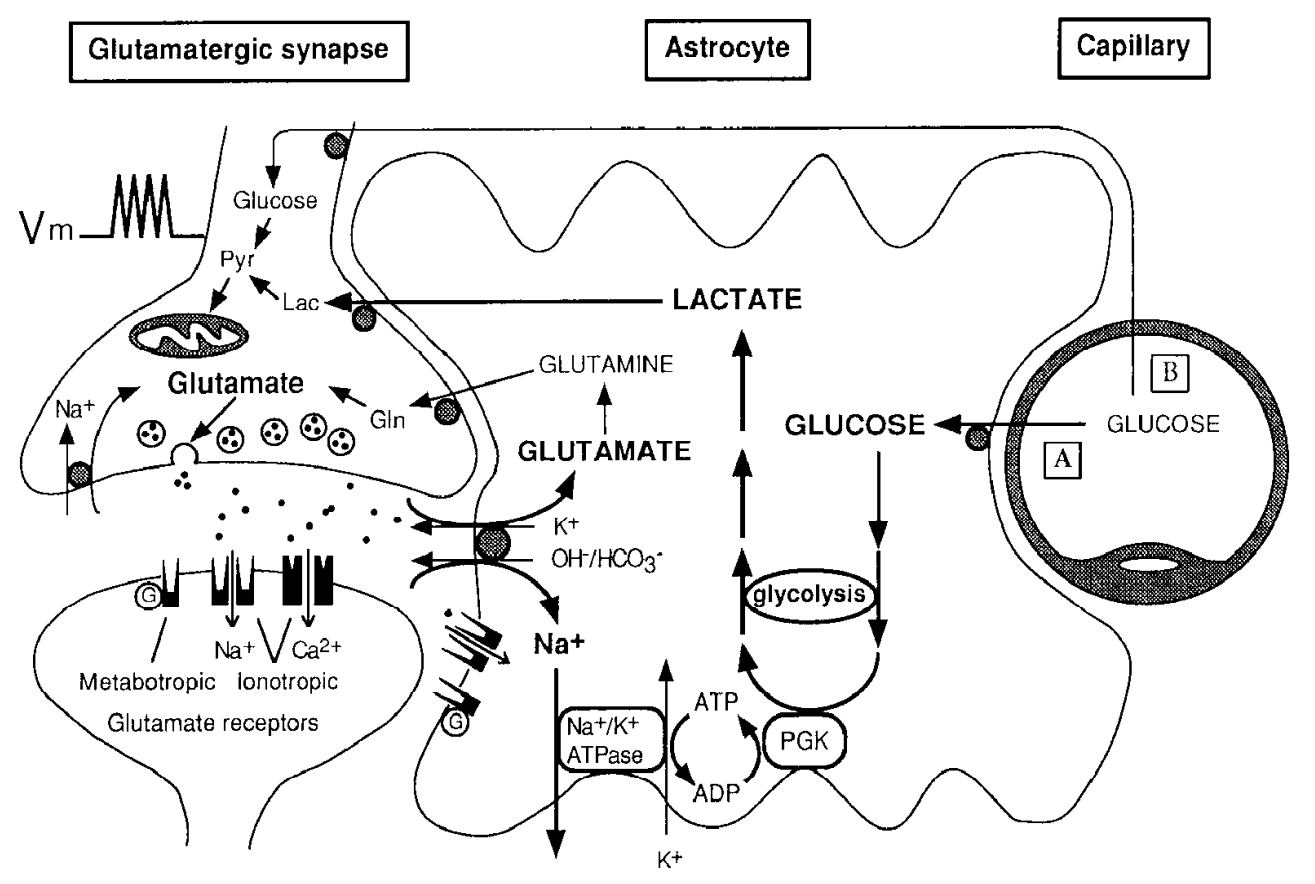

cellular concentration of $\mathrm{Na}^{+}$, which can reach $10-20 \mathrm{~mm}$ (Bowman and Kimelberg, 1984; Kimelberg et al., 1993). The stimulation of astrocyte glucose uptake is inhibited by preincubation of the astrocytes with the specific glutamate transporter inhibitor DL-threo- $\beta$-hydroxyaspartate (THA); replacement of $\mathrm{Na}^{+}$by choline in the medium also inhibits glucose uptake (Pellerin and Magistretti, 1994). These results clearly indicate a tight coupling between $\mathrm{Na}^{+}$-dependent glutamate uptake and glucose utilization by astrocytes (Fig. 3). A similar coupling between Na-dependent glutamate uptake and glucose utilization has been confirmed recently in rat astrocytes by Sokoloff and colleagues (Takahashi et al., 1995). Analysis of the intracellular molecular mechanism(s) of this coupling points at a critical involvement of $\mathrm{Na}^{+} / \mathrm{K}^{+}$-ATPase, as indicated by the complete inhibition by ouabain of glutamateevoked 2-DG uptake in astrocytes (Pellerin and Magistretti, 1994). The astrocytic $\mathrm{Na}^{+} / \mathrm{K}^{+}$-ATPase responds predominantly to increases in intracellular $\mathrm{Na}^{+}$, for which it shows a $K_{\mathrm{m}}$ of $\sim 10 \mathrm{~mm}$ (Kimelberg et al., 1978; Erecinska and Dagani, 1990). Because in cultured astrocytes, the intracellular $\mathrm{Na}$ ' concentration $\left([\mathrm{Na}]_{i}\right)$ ranges from 10 to $20 \mathrm{~mm}$ (Kimelberg et al., 1993), $\mathrm{Na}^{+} / \mathrm{K}^{+}$ATPase is set to be activated when $\left[\mathrm{Na}^{+}\right]_{i}$ rises concomitantly with glutamate uptake (Bowman and Kimelberg, 1984). Indeed, an increase in [ $\left.\mathrm{Na}^{+}\right]_{i}$ evoked by the $\mathrm{Na}$ ionophore monensin stimulates 2-DG uptake into astrocytes in an ouabain-sensitive manner (Yarowsky et al., 1986), indicating that a major determinant of glucose utilization by astrocytes is the activity of $\mathrm{Na}^{-1} / \mathrm{K}^{+}$-ATPase (Brookes and Yarowsky, 1985). In this context, it is important to note that in vivo, the mechanism that accounts primarily for the 2-DG uptake induced by neuronal activity is the $\mathrm{Na}^{1} / \mathrm{K}^{+}$-ATPase aclivity (Mala et al., 1980).

There is ample evidence in the literature indicating that in a variety of tissues, including the brain, kidney, vascular smooth muscle, and erythrocytes, activation of $\mathrm{Na}^{+} / \mathrm{K}^{+}$-ATPase activity stimulates glycolysis, i.e., glucose uptake and lactate production (Parker and Hoffman, 1967; Paul et al., 1979; Lipton and Robacker, 1983; Lynch and Balaban, 1987). That glutamate stimulates lactate production and release by astrocytes (with an $\mathrm{EC}_{50}$ of $70 \mu \mathrm{M}$ ) (Pellerin and Magistretti, 1994) is consistent with this evidence.

\section{Nature of the metabolite produced from glucose by glial cells to fuel neurons}

The view that emerges from the experiments reviewed thus far is that glucose uptake and phosphorylation in the nervous system occur predominantly in glial cells. Neurons also take up and phosphorylate glucose and express glucose transporters (Maher et al., 1994; Nagamatsu et al., 1994) and hexokinase (Kao-Jen and Wilson, 1980). However, as reviewed below, the preferred substrate for the tricarboxylic acid (TCA) cycle in neurons appears to be lactate (or alanine for the honeybee drone retina), implying that glucose taken up and phosphorylated by neurons is preferentially processed through other metabolic pathways, such as glycolysis or the pentose phosphate pathway (PPP). Supporting this view is evidence that in rod outer segments, the PPP is 
essential for the maintenance of the visual cycle ( $\mathrm{Hsu}$ and Molday, 1994). In addition, the production of reducing equivalents, namely reduced nicotinamide-adenine dinucleotide phosphate (NADPH), through the PPP appears to be a significant mechanism to scavenge oxygen free radicals produced by the oxidative activity of neurons (Ben-Yoseph et al., 1994). Here, we will review in more detail the evidence that the glycolytic products lactate (in the mammalian central nervous system) and alanine (in the honeybee drone retina) are released by glial cells and provide adequate energy substrates for neurons.

There is ample experimental evidence indicating that lactate and pyruvate are adequate energy substrates for brain tissue in vitro (McIlwain, 1953; Ide et al., 1969; Teller et al., 1977; Schurr et al., 1988). Thus, synaptic activity can be maintained in cerebral cortical slices with lactate or pyruvate as the only substrate provided (Mcllwain, 1953; Mcllwain and Bachelard, 1985; Schurr et al., 1988). Neurodegeneration of hippocampal slices induced by glucose removal is prevented by addition of lactate to the perfusing medium (Izumi et al., 1994).

Quantitatively, lactate is the primary metabolic intermediate released by cultured astrocytes, at a rate of $15-30 \mathrm{nmol} \cdot \mathrm{mg}$ of protein ${ }^{1} \cdot \min ^{-1}$ (Walz and Muckerji, 1988; Dringen et al., 1993a). Other, quantitatively less important intermediates released by astrocytes are pyruvate (at a rate $\sim 10$-fold lower than lactate), $\alpha$-ketoglutarate, citrate, and malate (Shank and Campbell, 1984; Selak et al., 1985; Sonnewald et al., 1991; Shank et al., 1993). Fluxes of lactate between astrocytes and neurons have been quantified in vitro, showing lactate utilization even in the presence of glucose (Larrabee, 1983, 1992, 1995). As noted earlier, when activation is mimicked in vitro by exposing cultured astrocytes to glutamate, a marked release of lactate and, to a lesser degree, pyruvate is observed (Pellerin and Magistretti, 1994). Glutamate evokes lactate release with the same potency and time course that it stimulates glucose utilization, which indicates that glutamate stimulates the glycolytic processing of glucose.

Studies in the well compartmented honeybee drone retina and in acutely isolated cell preparations from guinea pig retina corroborate such metabolic fluxes by which glucose taken up by glia is converted into glycolytic products that fuel neurons. The development of a simple preparation of the guinea pig retina, consisting of acutely isolated Müller cells (the predominant glial element in the vertebrate retina) still attached to photoreceptors, was of particular value for the analysis of such metabolic fluxes (PoitryYamate ct al., 1995). The interest in this preparation comes from observation that the structural and functional relationships and the polarity of both glia and photoreceptors are preserved after isolation and can be analyzed for several hours in vitro. This cell model has been used to obtain quantitative experimental evidence supporting the metabolic flux of lactate and amino acids between glial cells and neurons. Thus, under aerobic conditions and in the presence of glucose in the medium, Müller cells intensely transform glucose to lactate, causing massive lactate release into the extracellular space (Poitry-Yamate et al., 1995). In addition, experiments using ${ }^{14} \mathrm{C}$-labeled lactate or glucose indicate that freshly isolated photoreceptor neurons preferentially utilize lactate rather than glucose as an energy substrate. This is illustrated by the fourfold higher rate of ${ }^{14} \mathrm{CO}_{2}$ production from $\left[{ }^{14} \mathrm{C}\right]$ lactate than from $\left[{ }^{14} \mathrm{C}\right]$ glucose (Poitry-Yamate et al., 1995). Quantitative analysis of radiolabeled substrate fluxes indicated that lactate produced from glucose by Müller cells and released into the extracellular space fuels the mitochondrial oxidative metabolism of photoreceptor neurons. Thus, $>90 \%$ of the lactate produced by solitary Müller cells from exogenous glucose is found in the bathing solution. The specific radioactivity (s.a.) of lactate released into the bathing solution by the cells is considerably higher than the s.a. of lactate remaining inside the cells. Lactate also is synthesized from glycogen present in the Müller cells. However, the lactate produced from glucose in the Müller cells is preferentially released into the extracellular space. These data demonstrate that in a purified preparation consisting of structurally and functionally coupled glial cells (Müller cells) and neurons (photoreceptors), stimulation increases the consumption of lactate by the neurons in a manner that is quantitatively in accord with the increase in their $\mathrm{O}_{2}$ consumption (Haugh et al., 1990), which shows that lactate provides a preferred substrate for oxidative phosphorylation.

The model of a metabolic compartmentation in which glucose taken up by astrocytes is converted glycolytically into lactate. which is then released into the extracellular space to be utilized by neurons, is consistent with the available biochemical and electrophysiological observations. This array of experimental evidence supports the model of cell-specific metabolic regulation illustrated in Figure 3. Several additional observations made in various cellular systems by using complementary techniques further support this model. For example, for lactate to be an adequate metabolic substrate for neurons, particularly during their stimulation, two additional conditions have to be fullfilled. First, an active lactate uptake by neurons has to exist; second, the enzymatic machinery allowing lactate to enter the TCA cycle has to be present in neurons. Both features recently have been shown to occur. Thus, in addition to the evidence for a preferential utilization of lactate by photoreceptors isolated from guinea pig retina, a lactate uptake system has been demonstrated in pure neuronal cultures of mouse cerebral cortex (Dringen et al., 1993b). Also, after conversion to pyruvate via a reaction catalyzed by lactate dehydrogenase (LDH), 1 mole of lactate can provide 18 moles of ATP via oxidative phosphorylation. Five isozymes of LDI exist. One of them is the $\mathrm{M}_{4}$ (muscle) homotetramer present in tissues that produce lactate glycolytically, and a second is the $\mathrm{H}_{4}$ (heart) homotetramer, which is enriched in tissues that use lactate ats a substrate. The other three isozymes are heterotetramers composed of different combinations of the $\mathrm{M}$ and $\mathrm{H}$ subunits and have intermediate functional properties. There is evidence indicating that the $M$ subunit is localized predominantly in astrocytes, whereas neurons are enriched in the $H$ subunit (Tholey et al., 1981). This observation, which has been confirmed recently in the human brain (Bittar et al., 1995), is consistent with a predominant lactate production by astrocytes and lactate utilization by neurons.

In vivo studies support the idea that during activation of a given brain area, glycolysis may transiently exceed the rate of oxidative phosphorylation. Thus, increases in lactate levels in the rat somatosensory cortex after forepaw stimulation have been demonstrated (Hossmann and Linn, 1987; Ueki et al., 1988). In addition, lactate levels assayed in vivo by microdialysis in freely moving rats increase in hippocampus and striatum after somatosensory stimulation (Schasfoort et al., 1988; Fellows et al., 1993). Studies with PET and 'H-MRS to be discussed below confirm the occurrence of glycolysis during neuronal activation.

Quantitative analyses performed in honeybee drone retina preparations by HPLC and HPLC-mass spectroscopy (HPLCMS) further confirm the utilization by neurons of glycolytic intermediates produced by glial cells. In these preparations, glucose6-phosphate formed predominantly in the glial cells is converted to pyruvate and subsequently transaminated to form alanine. (The 


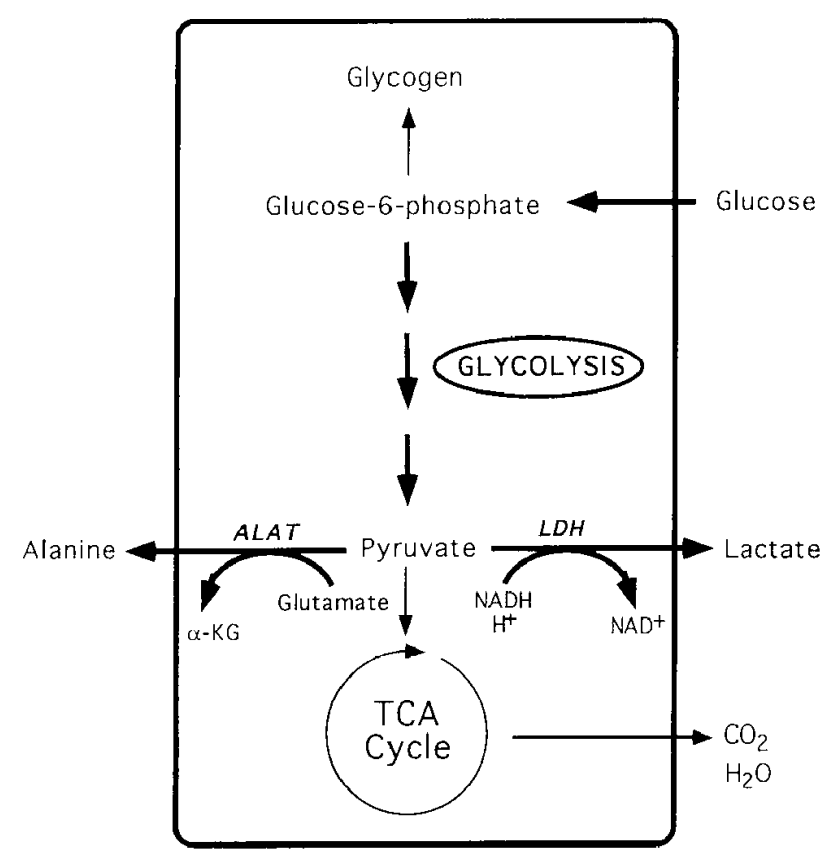

Figure 4. Simplified representation of the metabolic pathways of glucose, with particular emphasis of the fate of pyruvate, the end-product of glycolysis.

honeybee drone retina does not produce lactate.) As shown in Figure 4, pyruvate that does not enter the TCA cycle can be either converted to lactate or transaminated to form alanine; this latter reaction is catalyzed by the combined action of alanine aminotransferase (ALAT) and cytosolic glutamate dehydrogenase (GDH) (Fig. 4). Both metabolic pathways of pyruvate are necessary to regencrate nicotinamide adenine dinucleotide $\left(\mathrm{N} \wedge \mathrm{D}^{+}\right)$ and, therefore, maintain the redox potential of the cell. This is particularly crucial for honeybee retinal glia hecause with the virtual absence of mitochondria in these cells, glycolysis proceeds anaerobically in the dark as well as during photostimulation (Brazitikos and Tsacopoulos, 1991). Thus, maintenance of an appropriate $\mathrm{NADH} / \mathrm{NAD}^{+}$ratio is essential to sustain a high glycolytic flux. Alanine synthesized in glia is released into the interstitial space and taken up by photoreceptors by a $\mathrm{Na}^{+}$dependent transport mechanism (Tsacopoulos et al., 1994). Quantitative determination of alanine in the interstitial fluid of the retina of live honeybee drones reveals a concentration of 31 $\mathrm{mm}$, a value well within the range of the $K_{\mathrm{m}}$ of the alanine uptake system (Cardinaud et al., 1994). In the photoreceptors, alanine is deaminated to pyruvate via a reaction catalyzed by the neuronal isoform of ALAT (Ruscak et al., 1982). Pyruvate then can enter the TCA cycle for complete oxydation (Fig. 4).

In summary, although plasma lactate does not represent an adequate metabolic substrate for the brain because of its limited permeability across the blood-brain barrier (Pardridge and Oldendorf, 1977), lactate formed within the brain parenchyma via glutamate-activated glycolysis in astrocytes can fulfill the energetic needs of neurons.

\section{Incorporation of glucose into glycogen in astrocytes and mobilization of glycogen during brain activity}

In the brain, glycogen is localized almost exclusively in astrocytes (Peters et al., 1991). Despite its low concentration in the central nervous system (between 20 and $40 \mathrm{nmol} / \mathrm{mg}$ of protein), the turnover rate of glycogen is extremely rapid and its levels are
Table 1. Induction of glycogenolysis by neurotransmitters in primary astrocyte cultures of mouse cerebral cortex

\begin{tabular}{lc} 
Neurotransmitter & $\mathrm{EC}_{50}(\mathrm{nM})$ \\
\hline VIP & 3 \\
PHI & 6 \\
Secretin & 0.5 \\
PACAP & 0.08 \\
Noradrenaline & 20 \\
Adenosine & 800 \\
ATP & 1300
\end{tabular}

PHI, Peptide histidine isoleucine; PACAP, pituitary adenylate cyclase-activating peptide.

finely tuned by synaptic activily. For example, marked decreases in synaptic activity during barbiturate-induced anesthesia cause marked increases in the glycogen content of the brain (Phelps, 1972). Extensive evidence for a very active and tightly regulated metabolism of glycogen in astrocytes has become available, further supporting the idea that astrocytes are the site of intense glucose metabolism. Thus, mouse cerebral cortical astrocytes synthesize glycogen from glucose at a rate of $5-10 \mathrm{nmol} \cdot \mathrm{mg}$ of protein $^{-1} \cdot \min ^{-1}$, causing steady-state levels of $30-60 \mathrm{nmol} / \mathrm{mg}$ of protein, which are very similar to glycogen levels measured in the rodent brain (Sagar et al., 1987; Sorg and Magistretti, 1991; Sorg and Magistretti, 1992). Experiments had indicated that specific ncurotransmitters promote glycogenolysis in slices prepared from different brain areas, including the cerebral cortex. Thus, the monoamines noradrenaline (NA), serotonin, and histamine, the peptide vasoactive intestinal peptide (VIP), and the purine adenosine all promote glycogenolysis in mouse cerebral cortical slices, the rate of which is dependent on transmitter concentration (Quach et al., 1978, 1980, 1982; Magistretti et al., 1981, 1986). The respective morphological characteristics of the monoaminergic afferents that globally innervate the cerebral cortex, on one hand, and those of the local and radially oriented intracortical VIP neurons, on the other hand, indicate the existence of two complementary neuronal systems that can mobilize glycogen in the cortex, one global, spanning functionally distinct cortical regions, and the other local, exerting its metabolic activity within cortical columns (Magistretti and Morrison, 1988; Magistretti, 1990). Similar observations were made in primary cultures of mouse astrocytes, in which an induction of glycogenolysis by NA, VIP, analogs of VIP peptide histidine isoleucine (PHI) and pituitary adenylate cyclase-activating peptide (PACAP), adenosine, and ATP was demonstrated (Sorg and Magistretti, 1991; Magistretti et al., 1993; Sorg et al., 1995) (Table 1). The initial rate of glycogenolysis induced by VIP and NA in astrocytes ranges from 5 to $10 \mathrm{nmol}$. mg of protein ${ }^{-1} \cdot \min ^{-1}$ (Sorg and Magistretti, 1991), a value that is remarkably close to the rate of glucose utilization of gray matter, as determined by the 2-DG autoradiographic method (Sokoloff et al., 1977). This concordance indicates that the glycosyl units mobilized in response to the two glycogenolysis-inducing neurotransmitters can provide quantitatively adequate substrates for the energy demands of the brain parenchyma. It is not clear yet whether the glycosyl units mobilized by glycogenolysis are used by astrocytes to meet their own energy demands during brain activity, or whether they are metabolized to a substrate such as lactate (Dringen et al., 1993a), which then is released for the use by neurons. Experimental results clearly indicate that glycogenolysis does not cause cultured astrocytes to release glucose (Dringen et al., 1993d). 
The honcybec drone retina also shows activity-coupled glyco. genolysis. As noted earlier, glycogen in this nervous tissue is tocalized exclusively in glia (at a concentration of $\sim 90 \mathrm{mg} / \mathrm{ml}$ of glia) (Evequôz-Mercier and Tsacopoulos, 1991). When a retinal slice is superfused with a medium lacking glucose, photoreceptors still respond to photostimulation and increase their oxygen consumption fourfold (Tsacopoulos and Poitry, 1982; Tsacopoulos et al., 1987), whereas the glycogen content of the slices is reduced (Evequôz-Mercier and Tsacopoulos, 1991). This type of experiment, which can be repeated over several hours, indicates that energy substrates can be mobilized from glial cells and oxidized in photoreceptor neurons, as indicated by the increase in oxygen consumption, to sustain their electrical activity. This inference has been confirmed by additional experiments in which photostimulation of photoreceptors bathed in a glucose-containing medium triggers a large rise in glycogen turnover (Evequôz-Mercier and Tsacopoulos, 1991). Similarly, in the mammalian retina, glycogen and glycogen-metabolizing enzymes are concentrated primarily in Müller cells. Acutely isolated Müller cells from juvenile guinea pig retina contain $\sim 180 \mathrm{nmol}$ of glycosyl units $/ \mathrm{mg}$ of protein, a value three- to sixfold higher than that measured in cultured astrocytes (Swanson et al., 1990; Sorg and Magistretti, 1991), and rodent brain (Sagar et al., 1987). The glycogen content of purified Müller cells maintained in the absence of glucose from the bathing solution decreases by $\sim 50 \%$ in 30 min (Poitry-Yamate and Tsacopoulos, 1992).

Glycogenolysis also has been demonstrated in vivo in rat brain after physiological activation of a modality-specific pathway (Swanson et al., 1992). This activity dependent glycogenolysis was revealed by a newly developed autoradiographic technique for the detection of glycogen (Swanson et al., 1992). Thus, repeated stimulation of the facial vibrissae caused a marked decrease in the density of glycogen-associated autoradiographic grains in the barrel fields of the rat somatosensory cortex and in their afferent thalamic nuclei (Swanson et al., 1992). These observations clearly indicate that the physiological activation of specific neuronal circuits causes the mobilization of glycogen in glial cells.

\section{Relevance of metabolic findings for functional brain imaging}

The 2-DG autoradiographic technique developed by Sokoloff and his colleagues has revealed two fundamental features of brainenergy metabolism: its regional heterogeneity, and its tight coupling to neuronal activity (Sokoloff, 1991). However, despite the tremendous gains in our knowledge of brain function both in experimental animals and, because of the development of the $\left[{ }^{18} \mathrm{~F}\right] 2-\mathrm{DG}$ PET method, in humans, the cellular localization and the biochemical mechanisms underlying the 2-DG-based signal had been unresolved. Indirect evidence suggested that the activity-dependent uptake of 2-DG occurs in the neuropil, i.e., in regions that are enriched in axon terminals, dendrites, and synapses ensheathed by astrocytic processes, rather than in regions hosting ncuronal pcrikarya (Kadekaro et al., 1985; Sokoloff, 1991). Given the complex intertwining of neural processes in the nervous system, this observation is particularly apparent in those circuits in which a clear-cut polarization of neural process exists (Roland, 1993). Thus, a striking example was provided by a study of Sokoloff and colleagues, who showed that when the sciatic nerve of anesthetized rats is stimulated, a frequency-dependent increase in 2-DG uptake occurs in the dorsal horn of the spinal cord (where afferent sensory axon terminals make synaptic contacts with second-order interneurons), but not in the dorsal root ganglion, where the cell bodies of the sensory neurons are localized (Kadekaro et al., 1985). Other evidence for a selective uptake of the tracer in the neuropil was obtaincd in well laminated central nervous system structures, such as the primate visual cortex and the hippocampus (Kennedy et al., 1976). The evidence obtained in simple and well compartmentalized nervous systems and in purified cell cultures clearly indicates that 2-DG uptake during neuronal activity occurs in glial cells. This conclusion does not question, of course, the validity of 2-DG-based techniques for mapping neuronal activity. Rather, it provides a cellular and molecular basis for these in vivo imaging procedures.

PET analyses indicate the occurrence of metabolic uncoupling during neuronal activation, in which an increased glucose utilization is not matched by a commensurate increase in oxygen consumption (Fox and Raichle, 1986; Fox et al., 1988). Accordingly, lactate production is observed by 'H-MRS during neuronal activation in humans (Prichard et al., 1991; Sappey-Marinier et al., 1992). These in vivo data converge to indicate that neuronal activation is linked to glycolysis leading to lactate production. The set of observations reviewed in this article provides a cellular localization for the site of lactate production-astrocytes metabolize glucose to lactate (or alanine in the insect retina) and release it as a metabolic substrate for neurons.

In this article, we have attempted to integrate recent experimental results obtained in a variety of preparations and using various experimental approaches. They converge to indicate the existence of cell-specific metabolic fluxes occurring in the brain, particularly during neuronal activation. The data highlight a pivotal role for glial cclls in coupling neuronal activity to energy metabolism and in transforming blood-borne glucose into metabolic substrates that can fuel neurons. In addition, the data provide a cellular and molecular model for the interpretation of unexpected findings obtained recently with functional-brain imaging techniques such as PET and 'H-MRS.

\section{REFERENCES}

Andriezen WI. (1893) On a system of fibre-like cells surrounding the blood vessels of the brain of man and mammals, and its physiological significance. Int Monatsschr Anat Physiol 10:532-540.

Barres BA (1991) New roles for glia. J Neurosci 11:3685-3694.

Ben Yoseph O, Boxer PA, Ross BD (1994) Oxidative stress in the central nervous system: monitoring the metabolic response using the pentose phosphate pathway. Dev Neurosei 16:328-336.

Bittar PG, Charnay Y, Kiraly M, Pellerin L, Bouras C, Magistretti PJ (1995) Selective distribution of lactate dehydrogenase (LDH) isoenzymes in neurons and astrocytes: evidence for activity-dependent metabolic trafficking. Soc Neurosci Abstr 21:1668.

Bouvier M, Szatkowski M, Amato $A, \Lambda t$ twell D (1992) The glial cell glutamate uptake carrier countertransports $\mathrm{pH}$-changing anions. Nature 360:471-474.

Bowman CL, Kimelberg HK (1984) Excitatory amino acids directly depolarize rat brain astrocytes in primary culture. Nature 311:656-659.

Brazitikos PD, Tsacopoulos M (1991) Metabolic signaling between photoreceptors and glial cells in the retina of the drone (Apis mellifera). Brain Res 567:33-41.

Brookes N, Yarowsky PJ (1985) Determinants of deoxyglucose uptake in cultured astrocytes: the role of the sodium pump. I Neurochem $44: 473-479$

Cardinaud B, Coles JA, Perrottet P, Spencer AJ, Osborne MP, Tsacopoulos M (1994) The composition of the interstitial fluid in the retina of the honeybee drone: implications for the supply of substrates of energy metabolism from blood to neurons. Proc R Soc Lond [Biol] 257:49-58.

Danbolt NC (1994) The high affinity uptake system for excitatory amino acids in the brain. Prog Neurobiol 44:377 396.

Dimitracos SA, Tsacopoulos M (1985) The recovery from a transient inhibition of the oxidative metabolism of the photoreceptors of the drone (Apris mellifera O). J Exp Biol 119:165-181. 
Dringen R, Gebhardt R. Hamprecht B (1093a) Glycogen in astrocytes: possible function as lactate supply for neighboring cells. Brain Res 623:208-214.

Dringen R, Wiesinger H, Hamprecht B (1993b) Uptake of L-lactate by cultured rat brain neurons. Neurosei Lett 163:5-7.

Erecinska M. Dagani F (1990) Relationships between the neuronal sodium/potassium pump and energy metabolism: effects of $\mathrm{K}^{+}, \mathrm{Na}^{+}$, and adenosine triphosphate in isolated brain synaptosomes. J Gen Physiol 95:591-616.

Evequôz-Mercier V. Tsacopoulos M (1991) The light-induced increase of carbohydrate metabolism in glial cells of the honcybee retina is not mediated by K novement nor by cAMP. J Gen Physiol 98:497-515.

Fellows LK, Boutelle MG. Fillenz M (1993) Physiological stimulation increases monoxidative glucose metabolism in the brain of the freely moving rat. J Neurochem 60:1258-1263.

Fonnum $\mathrm{F}$ (1984) Glutamate: a neurotransmitter in mammalian brain. J Neurochen 42:1-11.

Fox PT, Raichle ME (1986) Focal physiological uncoupling of ecrebral blood flow and oxidative metabolism during somatosensory stimulation in human subjects. Proc Natl Acad Sci USA 83:1140-1144.

Fox PT, Ratichle ME, Mintun MA, Dence C (1988) Nonoxidative glucose consumption during focal physiologic neural activity. Science 241:462-464.

Golgi C (1886) Sulla fine anatomia degli organi centrali del sisterna nervoso. Milinno: Hoepli.

Haugh LM, Linsenmeier RA. Goldstick TK (1990) Mathematical models of the spatial distribution of retinal oxygen tension and consumption, including changes upon illumination. Ann Biomed Eng 18:19-36.

Hossmann KA. Linn F (1987) Regional energy metabolism during functional activation of the brain, J Cereb Blood Flow Metab 7:S297-S290.

Hsu S-C. Molday RS (1994) Glucose metabolism in photoreceptor outer segments. J Biol Chem 269:17954-17959.

Ide T, Steinke J, Cahill Jr GF (1969) Metabolic interactions of glucose, lactate, and $\beta$-hydroxybutyrate in rat brain slices. Am J Physiol 217:784-792.

Izumi Y. Benz AM, Zorumski CF, Olney JW (1994) Effects of lactate and pyruvate on glucose deprivation in rat hippocampal slices. NeuroReport 5:617-620.

Kato-Jen J. Wilson JE (1980) Localization of hexokinase in neural tissue: electron microscopic studies of rat cerebellar cortex. J Neurochem $35: 667-678$.

Kaldekaro M. Crane AM. Sokoloff L (1985) Differential effects of electrical stimulation of sciatic nerve on metabolic activity in spinal cord and dorsal root ganglion in the rat. Proc Natl Acad Sci USA 82:60)10-6013.

Kanai Y, Smith ( $\mathrm{P}$, Hediger MA (1994) A new family of neurotransmitter transporters: the high-alfinity glutamate transporters. FASEB J $8: 1450-1459$.

Kanner BI (1993) Glutamate transporters from brain: a novel neurotransmitter transporter family. FEBS Lett 325:95-99.

Kemedy C. Des Rusiers MH. Sakurada O, Shinohara M. Reivich M, Jehle JW, Sokoloff L (1976) Metabolic mapping of the primary visual system of the monkey by means of the atutoradiographic $\left[{ }^{1+} \mathrm{C}\right] \mathrm{de}$ dexyglucose technicue. Proc Natl Acad Sci USA 73:4230-4234.

Kimelberg HK, Narumi S, Biddlecome S, Bourke RS (1978) $\mathrm{Na}^{+} / \mathrm{K}^{+}$ATPasc, ${ }^{*} \mathrm{Rb}$ ' transport and carbonic anhydrasc activity in isolated brain cells and cultured astrocytes. In: Dynamic properties of glial cells (Schoffenicls E, Franck G, Towers DB, Hertz L, eds), pp 347-357. New York: Pergamon.

Kimelberg HK. Jalonen T, Walz W (1993) Regulation of brain microenvironment: transmitters and ions. In: Astrocytes: pharmacology and function (Murphy S, ed), pp 193-228. San Diego: Academic.

Kuffler SW. Nicholls JG, Orkand RK (1966) Physiological properties of glial cells in the central nervous system of amphibia. J Neurophysiol $29: 768-787$.

Larrabee MG (1983) I actate uptake and release in the presence of glucosc by sympathetic ganglia of chicken embryos and by neuronal and nonneuronal cultures prepared from these ganglia. J Neurochem 40:1237-1250.

Larrabec MG (1992) Extracellular intermediates of glucose metabolism: fluxes of endogenous lactate and alanine through extracellular pools in embryonic sympathetic ganglia. J Neurochem 59:1041-1052.

Larrabee MG (1905) Lactate metabolism and its effects on glucose metabolism in an excised neural tissus. J Neurochem 64:1734-1741.
Lipton P, Heimbach CJ (1978) Mechanism of extracellular K' stimulation of protein synthesis in the in vitro hippocampus. J Neurochem 31:1299-1308

Lipton P, Robacker K (1983) Glycolysis and brain function: [K ' 1 , stimulation of protein synthesis and $\mathrm{K}^{+}$uptake require glycolysis. Fed Proc 4?.2875-2880

Lopes-Cardozo M, Larsson OM, Schousboc A (1986) Acetoacetate and glucose as lipid precursors and energy substrates in primary cultures of astrocytes and neurons from mouse cerebral cortex. J Neurochem 46:773-778.

Lynch RM, Balaban RS (1987) Coupling of aerobic glycolysis and $\mathrm{Na}^{4}$ $\mathrm{K}^{+}$-ATPase in renal cell line MDCK. Am J Physiol 253:C269-C276.

Magistretti PJ, Morrison JH, Shoemaker WJ, Sapin V, Bloom FE (1981) Vasoactive intestinal polypeptide induces glycogenolysis in mouse cortical slices: a possible regulatory mechanism for the local control of energy metabolism. Proc Natl Acad Sci USA 78:6535-6539.

Magistretti PJ, Hof PR, Martin JL (1986) Adenosine stimulates glycogenolysis in mouse cerebral cortex: a possible coupling mechanism between neuronal activity and energy metabolism. J Neurosci 6:2558-2562.

Magistretti PJ, Morrison JH (1988) Noradrenaline- and vasoactive intestinal peptide-containing neuronal systems in neocortex: functional convergence with contrasting morphology. Neuroscience 24:367-378.

Magistretti PJ (1990) VIP neurons in the cerehral cortex. Trends Pharmacol Sci 11:250-254.

Magistretti PJ, Sorg O, Martin JL (1993) Regulation of glycogen metabolism in astrocytes: physiological, pharmacological, and pathologicat aspects. In: Astrocytes: pharmacology and function (Murphy S, ed), pp 243-265. San Diego: Academic.

Maher F, Vannucci SJ, Simpson IA (1994) Glucose transporter proteins in the brain. FASEB J 8:1003-1011.

Mata M, Fink DJ, Gainer H, Smith CB, Davidsen L, Savaki II, Schwartz WJ, Sokoloff L (1980) Activity-dependent energy metabolism in rat posterior pituitary primarily reflects sodium pump activity. J Neurochem 34:213-215.

McIlwain H (1953) Substances which support respiration and metabolic response to electrical impulses in human cerebral tissues. J Neurol Neurosurg Psychiatry 16:257-266.

Mcllwain H, Bachelard HS (1985) Biochemistry and the central nervous system, pp 54-83. New York: Churchill Livingstone.

Murphy S (1993) Astrocytes: pharmacology and function. San Diego: Academic.

Nagamatsu S, Sawa H, Inoue N, Nakamichi Y, Takeshima H, Hoshino T (1994) Gene expression of GLUT3 glucose transporter regulated by glucose in vivo in mouse brain and in vitro in neuronal cell cultures from rat embryos. Biochem J 300:125-131.

Nicholls JG, Martin AR, Wallace BG (1992) From ncuron to brain, pp 171-183. Sunderland, MA: Sinauer.

Pardridge WM, Oldendorf WH (1977) Transport of metabolic substrates through the bleod-brain barrier. J Neusochern 28:5-12.

Parker JC, Hoffman JF (1967) The role of membranc phosphoglycerate kinase in the control of glycolytic rate by active cation transport in human red blood cells. J Gen Physiol 601:893-916.

Paul RJ, Bauer M, Pease W (1979) Vascular smooth muscle: acrobic glycolysis linked to sodium and potassium transport processes. Science 206:1414-1416.

Pearce B (1993) Amino acid receptors. In: Astrocytes: pharmacology and function (Murphy S, ed), pp 47-66. San Diego: Academic.

Pellerin L, Magistretti PJ (1994) Glutamate uptake into astrocytes stimulates aerobic glycolysis: a mechanism coupling neuronal activity to glucose utilization. Proc Natl Acad Sci USA 91:10625-10629.

Pellerin L, Martin J-L, Magistretti PJ (1995) Deoxyglucose uptake and c-fos expression, two markers of neural activation, are differentially stimulated by glutamate in astrocytes and neurons in vitro. Soc Neurosci Abstr 21:580.

Peters A, Palay SL, de Webster $H$ (1991) The fine structure of the nervous system: neurons and their supporting cells. New York: Oxford UP.

Phelps CH (1972) Barbiturate-induced glycogen accumulation in brain: an electron microscopic study. Brain Res 39:225-234.

Poitry-Yamate C, Tsacopoulos M (1991) Glial (Müller) cells take up and phosphorylate $\left[{ }^{3} \mathrm{H}\right] 2$-deoxy-D-glucose in a mammalian retina. Neurosci Lett 122:241-244. 
Poitry-Yamate CL, Tsacopoulos M (1992) Glucose metabolism in freshly isolated Müller glial cells from a mammalian retina. J Comp Neurol 320:257-266.

Poitry-Yamate CL, Poitry S, Tsacopoulos M (1995) Lactate released by Müller glial cells is metabolized by photoreceptors from mammalian retina. J Neurosci 15:5179-5191.

Prichard J, Rothman D, Novotny E, Petroff O, Kuwabara T, Avison M, Howseman A, Hanstock C, Shulman R (1991) Lactate rise detected by 'H NMR in human visual cortex during physiologic stimulation. Med Sci 88:5829-5831.

Quach TT, Rose C, Schwartz JC (1978) [ $\left.{ }^{3} \mathrm{H}\right]$ Glycogen hydrolysis in brain slices: responses to neurotransmitters and modulation of noradrenaline receptors. J Neurochem 30:1335-1341.

Quach TT, Duchemin AM, Rose C, Schwartz JC (1980) $\left[{ }^{3} \mathrm{H}\right]$ Glycogen hydrolysis elicited by histamine in mouse brain slices: selective involvement of $\mathrm{H}_{1}$-receptors. Mol Pharmacol 17:301-308.

Quach TT, Rose C, Duchemin AM, Schwartz JC (1982) Glycogenolysis induced by serotonin in brain: identification of a new class of receptors. Nature 298:373-375.

Roland P (1993) Brain activation. New York: Wiley-Liss.

Ruscak M, Orlicky J, Zubor V, Hager H (1982) Alanine aminotransferase in bovine brain: purification and properties. $J$ Neurochem $39: 210216$

Sagar SM, Sharp FR, Swanson RA (1987) The regional distribution of glycogen in rat brain fixed by microwave irradiation. Brain Res 417:172-174.

Sala L (1891) Zur feineren anatomic des grossen seepferdefusses. Zeitschr Wissenschaftl Zool 1:18-45.

Sappey-Marinicr D, Calabrese G, Fein G, Hugg JW, Biggins C, Weiner MW (1992) Effect of photic stimulation on human visual cortex lactate and phosphates using ${ }^{1} \mathrm{H}$ and ${ }^{31} \mathbf{P}$ magnetic resonance spectroscopy. J Cercb Blood Flow Metab 12:584-592.

Schasfoort EMC, DeBruin LA, Korf J (1988) Mild stress stimulates rat hippocampal glucose utilization transiently via NMDA receptors, as assessed by lactography. Brain Res 475:58-63.

Schurr A, West CA, Rigor BM (1988) Lactate-supported synaptic function in the rat hippocampal slice preparation. Science 240:1326-1328.

Selak I, Skaper S, Varon S (1985) Pyruvate participation in the low molecular weight trophic activity for CNS neurons in glia-conditioned medium. J Neurosci 5:23-28.

Shank RP, Campbell GLM (1984) Alpha-ketoglutarate and malate uptake and metabolism by synaptosomes: further evidence for an astrocyte-to-ncuron metabolic shuttle. J Neurochem 42:1153-1161.

Shank RP, Leo GC, Ziclke HR (1993) Cerebral metabolic compartmentation as revealed by nuclear magnetic resonance analysis of D-[1-1.3 C]glucose metabolism. J Neurochem 61:315-323.

Sokoloff L, Reivich M, Kennedy C, Des Rosiers MH, Patlak CS, Pettigrew KD, Sakurada O, Shinohara M (1977) The $\left[{ }^{14} \mathrm{C}\right]$ dcoxyglucose method for the measurement of local cerebral glucose utilization: theory, procedure, and normal values in the conscious and anesthetized albino rat. J Neurochem 28:897-916.

Sokoloff L, Kennedy C, Smith CB (1989) The $\left[{ }^{14} \mathrm{C}\right]$ deoxyglucose method for measurement of local cerebral glucose utilization. In: Neuromethods, Vol 11, Carbohydrates and energy metabolism (Boulton AA, Baker GB, Butterworth RF, eds), pp 155-193. Clifton, NJ: Humana.

Sokoloff L (1991) Relationship between functional activity and energy metabolism in the nervous system: whether, where and why? In: Brain work and mental activity (Lassen NA, Ingvar DH, Raichle ME, Friberg L, eds), pp 52-64. Copenhagen: Munksgaard.
Sonnewald U, Westergaard N, Krane J, Unsgåard G, Petersen SB, Schousboe A (1991) First direct demonstration of preferential release of citrate from astrocytes using $\left[{ }^{1.3} \mathrm{C}\right] \mathrm{NMR}$ spectroscopy of cultured neurons and astrocytes. Neurosci Lett 128:235-239.

Sorg O, Magistretti PJ (1991) Characterization of the glycogenolysis elicited by vasoactive intestinal peptide, noradrenaline and adenosine in primary cultures of mouse cerebral cortical astrocytes. Brain Res 563:227-233.

Sorg O, Magistretti PJ (1992) Vasoactive intestinal peptide and noradrenaline exert long-term control on glycogen levels in astrocytes: blockade by protein synthesis inhibition. J Neurosci 12:4923-4931.

Sorg O, Pellerin L, Stolz M, Beggah S, Magistretti P (1995) Adenosine triphosphate and arachidonic acid stimulate glycogenolysis in primary cultures of mouse cerebral cortical astrocytes. Neurosci Lett 188:109-112.

Swanson RA, Yu ACH, Chan PH, Sharp FR (1990) Glutamate increases glycogen content and reduces glucose utilization in primary astrocyte culture. J Neurochem 54:490-496.

Swanson RA, Morton MM, Sagar SM, Sharp FR (1992) Sensory stimulation induces local cerebral glycogenolysis: demonstration by autoradiography. Neuroscience 51:451-461.

Takahashi S, Driscoll BF, Law MJ, Sokoloff L (1995) Role of sodium and potassium ions in regulation of glucose metabolism in cultured astroglia. Proc Natl Acad Sci USA 92:4616-4620.

Teller DN, Banay-Schwartz M, Deguzman T, Lajtha A (1977) Energetics of amino acid transport into brain slices: effects of glucose depletion and substitution of Krebs' cycle intermediates. Brain Res 131:321-334.

Tholey G, Roth-Schechter BF, Mandel P (1981) Activity and isoenzyme pattern of lactate dehydrogenase in neurons and astroblasts cultured from brains of chick embryos. J Neurochem 36:77-81.

Tsacopoulos M, Poitry S (1982) Kinctics of oxygen consumption after a single flash of light in photoreceptors of the drone (Apis mellifera). J Gen Physiol 80:19-55.

Tsacopoulos M, Coles JA, Van der Werve G (1987) The supply of metabolic substrate from glia to photoreceptors in the retina of the honeybec drone. J Physiol (Paris) 82:279-287.

Tsacopoulos M, Evêquoz-Mercier V, Perrottet P, Buchner E (1988) Honeybee retinal glial cells transform glucose and supply the neurons with metabolic substrates. Proc Natl ^cad Sci USA 85:8727-8731.

Tsacopoulos M, Veuthey A-L, Saravelos SG, Perrottet P, Tsoupras G (1994) Glial cells transform glucose to alanine, which fuels the neurons in the honcybee retina. J Neurosci 14:1339-1351.

Tsacopoulos M, Poitry S (1995) Metabolite exchanges and signal trafficking between glial cells and neurons in the insect retina. In: Neuron-glia interrelations during phylogeny. II. Plasticity and regeneration (Vernadakis A, Roots B, eds), pp 79-94. Totowa, NJ: Humana.

Ucki M, Linn F, Hossmann KA (1988) Functional activation of cerebral blood flow and metabolism before and after global ischemia of rat brain. J Cereb Blood Flow Metab 8:486-494.

Veuthey AL, Tracopoulus M, Millan de Ruiz L, Perrotlet P (1994) Cellular and subcellular localization of hexokinase, glutamate dehydrogenase and alanine aminotransferase in the honeybee drone retina. J Neurochem 62:1939-1946.

Walz W, Muckerji S (1988) Lactate release from cultured astrocytes and neurons: a comparison. Glia 1:366-370.

Yarowsky PJ, Boyne AF, Wierwille R, Brookes N (1986) Effect of monensin on deoxyglucose uptake in cultured astrocytes: energy metabolism is coupled to sodium entry. J Neurosci 6:859-866. 